\begin{tabular}{|c|c|c|c|c|c|}
\hline MUNIBE Antropologia-Arkeologia & $n^{\circ} 71$ & $137-150$ & DONOSTIA & 2020 & ISSN 1132-2217 • eISSN 2172-4555 \\
\hline
\end{tabular}

\title{
Los baptisterios de Egitania (Idanha-a-Velha, Portugal). Contexto arqueológico y cultural
}

\author{
The baptisteries from Egitania (Idanha-a-Velha, Portugal). \\ Archaeological and cultural context
}

PALABRAS CLAVES: Cristianismo primitivo, Arqueología Cristiana, Bautismo, Piscinas Bautismales, Alta Edad Media. GAKO-HITZAK: Kristautasun primitiboa, arkeologia kristaua, bataioa, bataioko igerilekuak, Goi Erdi Aroa. KEY WORDS: Early Christianity, Christian archaeology, Baptism, Baptismal fonts, Early Medieval Age.

\section{Tomas CORDERO RUIZ(1), Catarina TENTE(2), Pedro C. CARVALHO( ${ }^{(3)}$ José CRISTÓVÃO(4), Patrícia DIAS ${ }^{(3)}$, Adolfo FERNÁNDEZ FERNÁNDEZ(4)}

\section{RESUMEN}

En el ámbito del proyecto de investigación IGAEDIS (Da civitas Igaeditanorum à Egitânia. A construção e evolução da cidade e a definição dos seus territórios da Época Romana até à doação dos Templários - séculos I a XII) se han realizado diferentes actuaciones arqueológicas en la actual aldea histórica de Idanha-a-Velha (Portugal). Además, la revisión de anteriores intervenciones, complementadas con la realización de dataciones absolutas, han permitido atribuir una cronología más temprana de la asignada hasta ahora a los dos "baptisterios" documentados en el yacimiento. Esta nueva lectura nos lleva a plantear un renovado marco de reflexión y crítica histórica, tanto de estas construcciones piscinas bautismales - como del contexto en el que se insertan. Un ejercicio presentado en este trabajo de manera diacrónica, con el objetivo de mejorar el conocimiento sobre la evolución histórica de este sitio arqueológico entre los siglos IV-VIII.

\section{LABURPENA}

IGAEDIS (Da civitas Igaeditanorum à Egitânia. A construção e evolução da cidade e a definição dos seus territórios da Época Romana até à doação dos Templários - séculos I a XII) ikerketa-proiektuaren baitan, Idanha-a-Velhako (Portugal) herrixka historikoan lan arkeologiko batzuk egin dira. Lehendik egindako lanen berrikusketak orain egindako datazio absolutuekin osatuta, aztarnategian dokumentatutako bi "bataiarriei" orain arte esleitu izan zaizkiena baino goiztiarragoa den kronologia zehaztu ahal izan zaie. Irakurketa berri horrek eraikuntza horien (bataioko igerilekuak) eta dagokien testuinguruaren gogoetarako eta kritika historikorako testuinguru berria mahaigaineratzera bultzatu gaitu. Lan hori modu diakronikoan azaltzen da hemen, IV-VIII. mendeen artean gune arkeologiko horrek izan zuen bilakaera historikoari buruz ditugun ezagutzak hobetzeko asmoz.

\section{ABSTRACT}

In the scope of the research project IGAEDIS (From the civitas Igaeditanorum to Egypt. The construction and evolution of the city and the definition of its territories from the Roman era until the donation of the Templars $-1^{\text {st }}$ to $12^{\text {th }}$ centuries) several archaeological activities have been carried out in the historic village of Idanha-a-Velha (Portugal). The project, as also the aim to review the previous archaeological interventions, studying the stratigraphy, the correlated archaeological artefacts and promoting several radiocarbon and OSL analysis. In what the two "baptisteries" concerns, the research permitted to review the chronology of these structures, that are earlier than the several chronologies proposed until now. These results implied a new reflection about meaning of the both baptismal fonts and their historical and religious contexts. In this paper is presented and interpretation of the archaeological contexts of these structures and is discussed their meaning within the scope of the urban changes that occurred in Idanha-a-Velha between $4^{\text {th }}$ to $7^{\text {th }}$ centuries

\footnotetext{
(1) IEM | NOVA FCSH. (Instituto de Estudos Medievais, Faculdade de Ciências Sociais e Humanas da Universidade Nova de Lisboa) Av. de Berna 26C, 1060-061 Lisboa, Portugal. Telf. +351 937886157 / +34 644591281. E-mail: tomascordero@fcsh.unl.pt

(2) IEM | NOVA FCSH. (Instituto de Estudos Medievais, Faculdade de Ciências Sociais e Humanas da Universidade Nova de Lisboa) Av. de Berna 26C, 1060-061 Lisboa, Portugal. Telf. +351 7908300 / +351968562582. E-mail: catarina.tente@fcsh.unl.pt

(3) FLUC | CEIS20. (Faculdade de Letras da Universidade de Coimbra | Centro de Estudos Interdisciplinares do século XX)

Largo da Porta Férrea. 3004-530 Coimbra. Portugal. Telf. +351239859900. E-mail: pedrooak@gmail.com

(4) Município de Idanha-a-Nova.

Praça do Município 6060-163 - Idanha-a-Nova, Portugal. Telf. +351277 202 900. E-mail: josecristovao@sapo.pt

(5) Município de Idanha-a-Nova.

Praça do Município 6060-163 - Idanha-a-Nova, Portugal. Telf. +351277 202 900. E-mail: adalgisa.dias@cm-idanhanova.pt

(6) Facultad de Historia. GEAAT. Universidade de Vigo.

Despacho n²8, 1 Andar, Ed. Olga Gallego, Campus As Lagoas, Ourense- España. Telf. +34 988387 262. E-mail: adolfo@uvigo.es
} 


\section{INTRODUCCIÓN}

El estudio de la llamada Sé de Santa María y de las diferentes estructuras documentadas en su entorno inmediato, entre las que destacan dos piscinas bautismales y las englobadas en el denominado Paço dos Bispos, ha monopolizado el interés de la investigación sobre el período altomedieval de la actual aldea de Idanha-a-Velha. A pesar del gran acervo historiográfico generado en relación con este tema, la mayor parte de los análisis realizados adolecen de una propuesta cronológica basada en datos puntuales. Por otra parte, cabe destacar que la historiografía idanhense está definida, a grandes rasgos, por la falta de consenso y por la formulación de hipótesis que presentan notables diferencias tanto en la interpretación como en la datación del registro material mencionado (Cordero, 2018: 113-116).

Un reciente trabajo sobre las piscinas bautismales de Idanha-a-Velha, alejado de los anteriores presupuestos histórico-artísticos y fundamentado en la aplicación del sistema estratigráfico combinado con diversos análisis arqueométricos, ha permitido enmarcarlas dentro de un nuevo contexto temporal (Fernández et al.,
2019). Este nuevo encaje precisa, no obstante, de una reflexión y una crítica histórica de mayor calado que englobe ambas estructuras en el yacimiento arqueológico donde se integran, ejercicio que presentamos en este análisis.

\section{DE CIVITAS IGAEDITANORUM A EGITANIA}

La actual aldea de Idanha-a-Velha se Iocaliza sobre la antigua ciudad romana de Igaedis, capital de la civitas Igaeditanorum. Un núcleo de nuevo cuño que, tras su fundación en el último tercio del siglo I a. C., ocuparía un lugar central dentro del esquema de ocupación romano en el interior de Lusitania, beneficiándose de su estratégica posición dentro del sistema viario provincial y de la presencia de importantes explotaciones auríferas en su territorio (Sánchez-Palencia y Pérez, 2005; Carvalho, 2012) (Fig. 1). Sin embargo, la información disponible sobre el antiguo núcleo romano, a excepción del área del foro (Carvalho, 2009), es todavía limitada (Cristóvão, 2005).

Entre los siglos $V$ y VI la ciudad formaría parte del reino suevo, tiempo en que comenzaría a ser conoci-

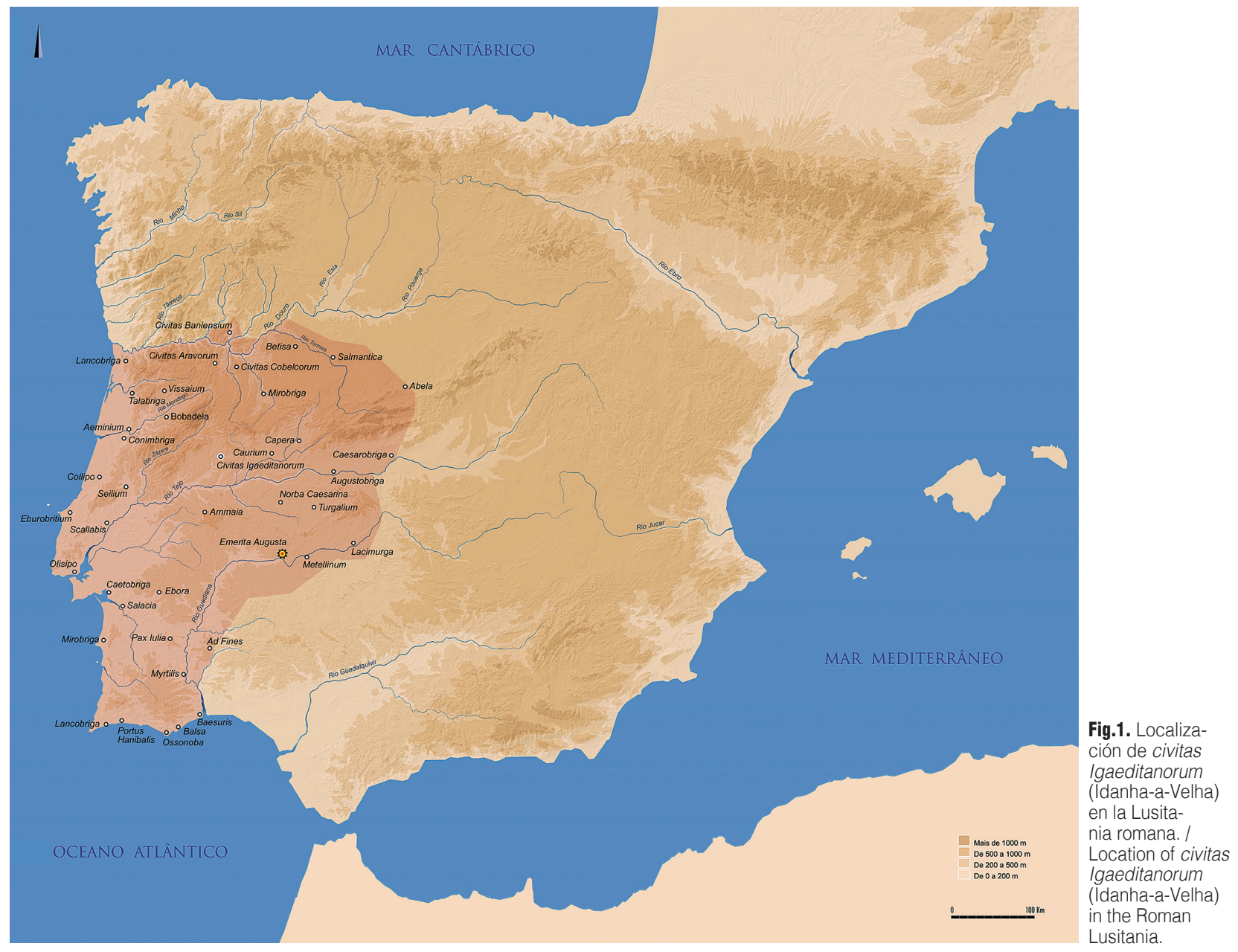


da como Egitania. La primera mención de este nombre está vinculada a su reconocimiento como sede episcopal en las actas del denominado Concilio de Lugo -c. 569-, aunque, probablemente, su fundación se produjese en un momento anterior. La diócesis egitana, al igual que sus homólogas, jugaría un importante papel como núcleo vertebrador del reino suevo hasta su desaparición en 585 (Díaz, 2011: 229-230), año en que el rey visigodo Leovigildo culminó su conquista. Acontecimiento que permitió su reintegración en el seno de la iglesia lusitana en la primera mitad del siglo VII (Cordero, 2019). La ciudad mantendría su relevancia dentro del reino visigodo, como parece indicar la importancia de su episcopado, presente en todos los concilios eclesiásticos celebrados entre los siglos VI y VII (Jorge, 2002: 75-76), y la constante acuñación de moneda en su ceca entre los reinados de Recaredo I y Rodrigo (Pliego, 2009: 127).

\section{HISTORIOGRAFÍA Y DESCRIPCIÓN DE LAS PISCINAS BAUTISMALES DE IDANHA-A-VELHA}

Entre las décadas de los 50 y los 70 del S. XX, F. de Almeida dirigió diferentes campañas de excavación en el entorno de la actual Sé de Santa María, en el transcurso de las cuales, en 1962, identificó una piscina bautismal de planta cruciforme. Estructura que fue considerada durante el resto de la centuria como parte del primer baptisterio de Idanha-a-Velha (Almeida, 1965). La actividad arqueológica en torno a esta construcción fue retomada a caballo entre los siglos XX y XXI por J. Cristóvão, quien pudo intervenir en zonas todavía no sondeadas y documentar con precisión la estratigrafía conservada en los alrededores de esta construcción (Fig. 2).
La estructura original del supuesto baptisterio sur es desconocida, conservándose como testimonio de este espacio su piscina bautismal (Fig. 3). Esta construcción presenta una planta cruciforme compuesta por: a) una piscina rectangular con suelo de opus signinum y placado marmóreo en las paredes laterales, a la que se descendía por unos escalones de planta semicircular y de los que sólo se han conservado dos en cada lado, b) separadas por un estrecho muro de ladrillo recubierto con placas de mármol se sitúan, a cada lado de la pila central, dos pequeñas piletas laterales de planta lobulada con fondo marmóreo y paredes recubiertas con mortero de cal, rematadas ambas por sendos lóbulos paralelos a la piscina central. Los peldaños esta última presentan un revestimiento de opus signinum en el que se pueden distinguir varias camadas sucesivas. Una explicación plausible a este hecho sería considerar esta superposición como prueba de diferentes revestimientos, lo cual indicaría un uso prolongado en el tiempo. No obstante, el análisis macroscópico de estas camadas -idénticas en color, granulometría y composición- señala que nos hallamos ante el mismo material de construcción. Situación que, probablemente, se relacione con una única actividad de aplicación sucesiva destinada a conseguir un mejor acabado y prevenir su agrietamiento.

F. de Almeida (1965: 134-135) estableció un paralelismo entre la piscina de Idanha-a-Velha y la documentada en la basílica turca de Side. Una base que le permitió fijar su datación en un momento anterior al Concilio de Lugo y a la creación de la sede episcopal egitana. Esta posibilidad no fue explorada posteriormente por F. de Almeida (1965: 136), quien acabó por considerar que esta fons era la prueba de que la Sé de
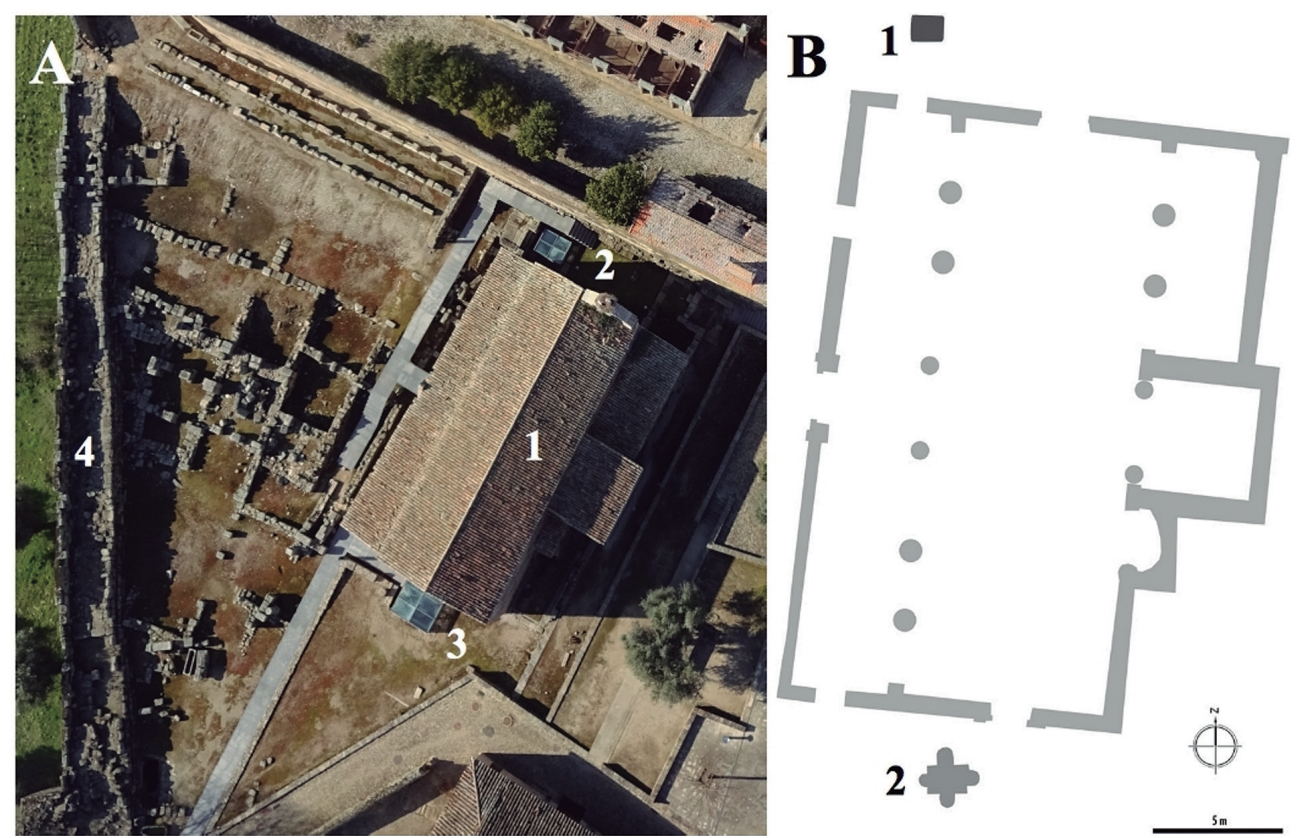

Fig.2. Iglesia de Santa María y localización de las piscinas bautismales. A: 1. Iglesia de Santa María, 2. Piscina bautismal norte, 3. Piscina bautismal sur, 4. Muralla de la ciudad. B: 1- Piscina bautismal norte, 2- Piscina bautismal sur. Church of Santa María and location of the baptismal fonts. A: 1 Church of Santa María, 2 North baptismal font, 3. South baptismal font, 4 . City wall. B: 1- North baptismal font, 2South baptismal font. 


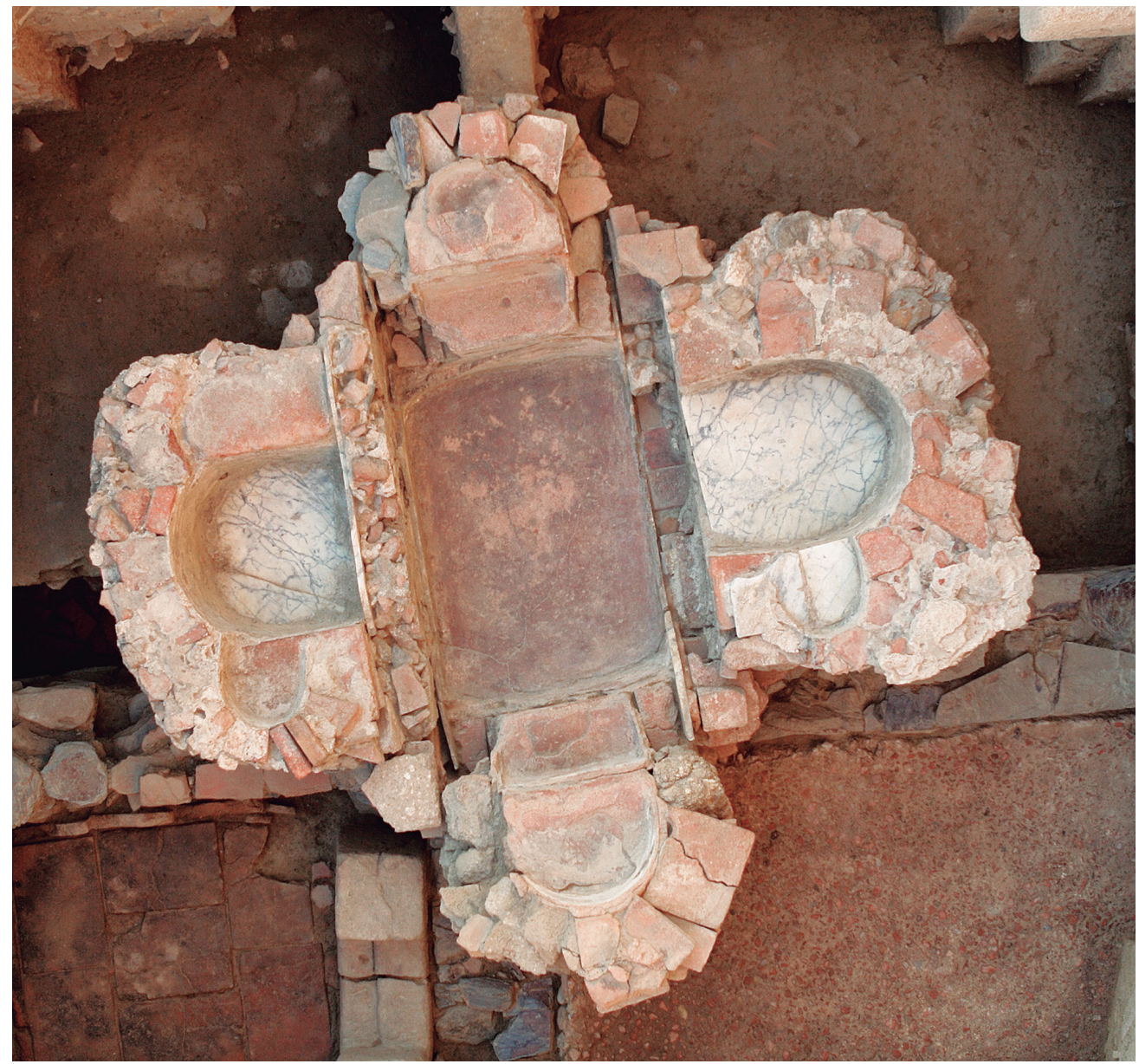

Fig.3. Piscina bautisma sur tras la finalización de los trabajos arqueológicos dirigidos por J. Cristovão. / Southern baptismal font after the completion of the archaeological works directed by J. Cristovão.
Santa María se correspondía con la catedral construida en el S. VI. La potencial influencia norteafricana en esta construcción fue señalada por P. de Palol (1967: 172), quien, además, destacó que las dos piletas adyacentes podrían dedicarse al bautismo infantil. Una idea mantenida por H. Schlunk y T. Hauschild (1978: 149-150) y, también, por Th. Ulbert (1978: 146-151), quien ahondaría en esta hipótesis vinculando su presencia con la generalización del bautismo infantil durante el S. VI (Ulbert, 1978: 175-179). Esta tesis fue rebatida por C. Godoy (1986: 132-133), que supeditó su funcionalidad con los lugares que ocuparían el oficiante y su ayudante durante el rito bautismal (Godoy, 1986: 135).

La propuesta cronológica de F. de Almeida (1965: 134-136) en relación con la piscina bautismal sur, establecida en base a criterios cronológicos histórico-artísticos, fue admitida durante los años siguientes (Ulbert, 1978: 153; Schlunk y Hauschild, 1978: 149-150; Ferreira de Almeida, 1986: 46). A pesar de las críticas sobre el fundamento de esta hipótesis (Godoy, 1995: 324) y de la aparición de nuevas teorías sobre la función y cronología de la Sé de Santa María (Torres, 1992; Real, 2000: 69-71), lo cierto es que esta estructura bautismal acabó por datarse, genéricamente, en época visigoda. De otro lado, cabe destacar que dentro de este debate se definió la desconexión estructural entre esta piscina y la actual Sé de Santa María (Torres, 1992: 179).

Las excavaciones arqueológicas dirigidas por J. Cristóvão (2002: 22) permitieron comprobar la relación de anterioridad de la fons sur con respecto a la construcción de la Sé de Santa María. Un dato en el que abundaría L. Caballero (2006: 270-271). Recientemente, I. Sánchez y J. Morín ${ }^{1}$ (2014: 70-72) han propuesto la inclusión de esta construcción bautismal en un espacio cuadrangular conectado con una iglesia que localizan al sureste de la Sé de Santa María y que dibujan igual que la del complejo religioso de la villa de Torre de Palma (Maloney y Hale 1996). Un paralelo señalado anteriormente por otros autores (Palol, 1967: 174-175; Schulnk y Hauschild, 1978: 149-150; Ulbert, 1978: 151-

\footnotetext{
${ }^{1}$ En los últimos años, las publicaciones de ambos investigadores sobre Idanha-a-Velha han sido variadas. No obstante, en este trabajo se utilizará esencialmente su primera monografía sobre el yacimiento (Sánchez y Morín, 2014), ya que es en ella donde presentan los puntos fundamentales sobre su reinterpretación de los restos arqueológicos localizados en torno a la Sé de Santa María.
} 
153). Además, vuelven a plantear su encaje cronológi$\mathrm{co}$, a través de criterios tipológicos, en la segunda mitad del S. VI, período en que datan la construcción de un complejo episcopal acorde con la nueva categoría de la ciudad (Sánchez y Morín, 2014: 70-89).

De otro lado, en la esquina exterior noroeste de la Sé de Santa María las excavaciones dirigidas por J. Cristóvão sacaron a la luz la segunda estructura bautismal de Idanha-a-Velha, el denominado baptisterio norte (Fig. 4). Esta área ya había sido excavada por $F$. de Almeida durante la década de los sesenta del S. XX, aunque sus resultados no fueron divulgados en profundidad (Almeida, 1977: 52). Esta piscina presenta una planta rectangular y conserva dos escalones en el lado oriental por sólo uno en lado occidental. El interior está cubierto por opus signinum salvo en el fondo de la construcción, donde se dispone, reutilizada, una placa de mármol blanco. En este sentido, cabe destacar que el resto de los materiales empleados en esta pila proceden, al igual que en la meridional, del expolio de construcciones anteriores (Cristóvão, 2002: 14-15).

La inclusión de esta estructura dentro del debate científico ha sido lógicamente menor debido a su reciente hallazgo. En primera instancia, J. Cristóvão (2002:
14-15) relacionó esta piscina con un edificio religioso, que no consiguió definir debido a la escasez de datos precisos, y estableció su datación entre el S. IV e inicios del S. V. Esta propuesta temporal fue discutida poco después. En primer lugar, P. A. Fernandes (2006: 63) consideró fechar la piscina en un momento posterior, coincidiendo con el paso del bautismo por inmersión al bautismo por aspersión, al tiempo que la incluía dentro de una construcción tripartita articulada con la división interior de la Sé de Santa María. Una edificación que supone debía rematarse por un ábside situado en el extremo opuesto de la piscina. Espacio que localiza, al igual que F. de Almeida (1977: 52), en una estancia con pavimento de opus signinum y donde, además, señala las huellas de un posible altar. En segundo lugar, L. Caballero (2006: 270-271) apuntó que la Sé de Santa María sería una construcción posterior a las piscinas sur y norte, proponiendo la continuidad estructural del actual edificio tanto por su frente norte como por el este y el sur. Por último, I. Sánchez y J. Morín (2014: 69-89) dan por válida la propuesta temporal de J. Cristóvão y la lectura arquitectónica de P. A. Fernandes, datos que les sirven para plantear la existencia de una basílica con baptisterio y planta tripartita que consideran el primer establecimiento cristiano de Idanha-a-Velha. Una

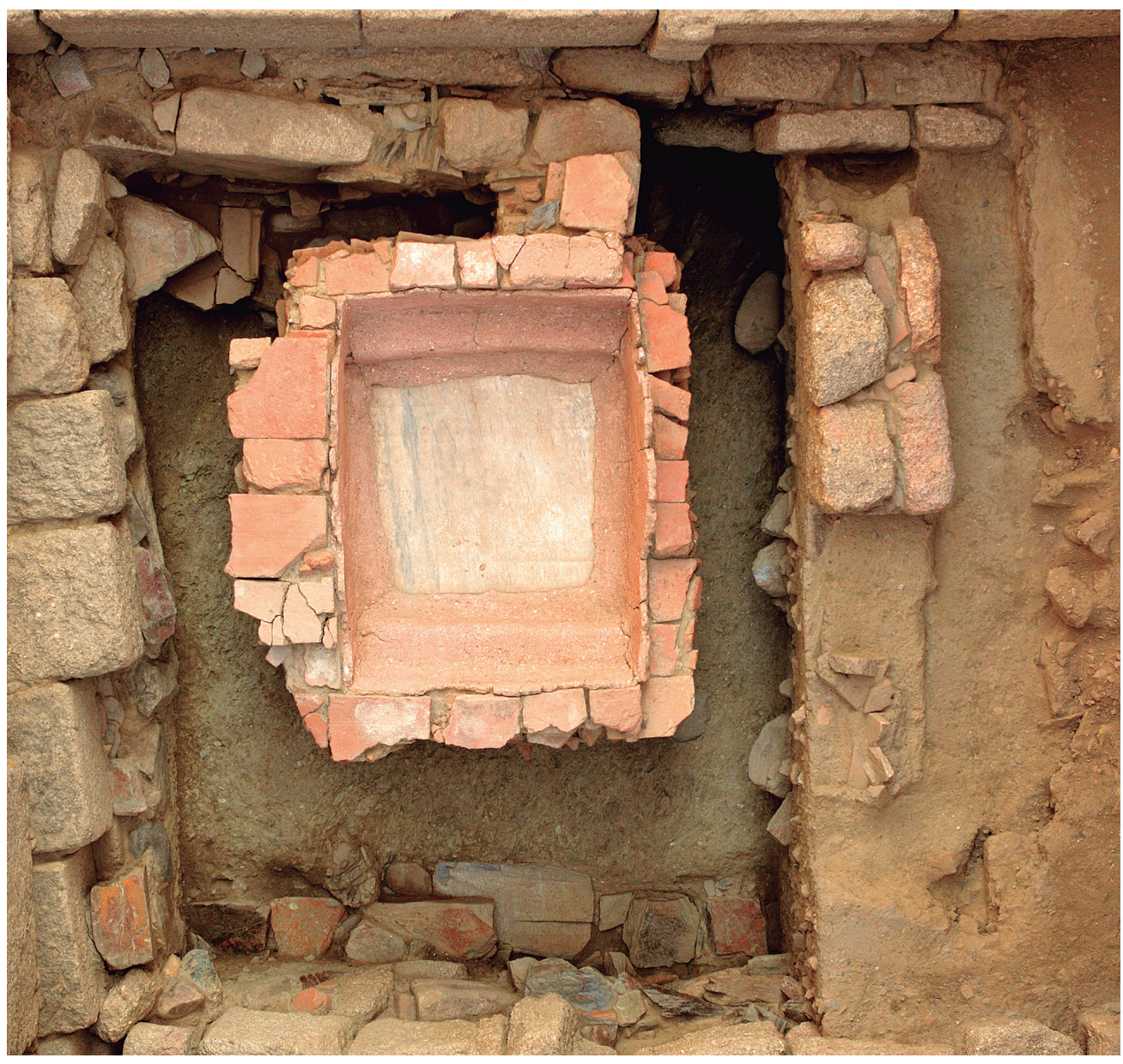

Fig.4. Vista cenital de la piscina bautismal norte tras la finalización de los trabajos arqueológicos dirigidos por J. Cristovão. / Zenithal view of the north baptismal font after the completion of the archaeological works directed by J. Cristovão. 
construcción que suponen sustituida en el siglo VI por la edificación de un gran complejo episcopal en el que integran la fons meridional.

\section{NUEVOS DATOS SOBRE LAS PISCINAS BAU- TISMALES IDANHENSES: ESTRATIGRAFÍA Y DATACIONES}

\subsection{La Piscina norte}

En la piscina bautismal norte, la secuencia estratigráfica más antigua documentada se relaciona con los restos de un probable espacio doméstico que puede encuadrarse temporalmente entre el período augusteo y la primera mitad del S. II (Fig. 5 - UEs 81, 69, 68, 67, 66 y 64). A continuación, se dispone una sucesión de diferentes estratos datados entre la segunda mitad del S. II y la primera mitad/mediados del S. IV (Fig. 5 - UEs 23/24, 39, 59, 61, 62), caracterizados por presentar un alto porcentaje de materiales de construcción -teja y ladrillo- y cerámica muy fragmentada, entre la que destaca la presencia de TS Africana C -ARS C - Hayes 50- y la ausencia de TS Hispánica Tardía. Estas unidades, probablemente rellenos de nivelación, son cortadas por la zanja de cimentación de la piscina bautismal (Fig. 5 - UEs 16 y 38). Actividad que en función de los materiales recogidos puede datarse a mediados del S. IV.

La estratigrafía identificada en el interior de esta estructura norte permite sugerir una fecha ligada a su amortización (Fig. 5 - UEs 57, 56 y 55) (Fernández et al.,
2019: 5700-5702). En este sentido, el registro cerámico documentado -TS Africana D1 (Hayes 58B), TS Africana C (Hayes 46 residual) y TS Hispánica Tardía (Ritt 8T y Drag. 37T) con varios fragmentos con decoración burilada- permitiría datarla entre finales del S. IV e inicios del S. V, como terminus post quem para el momento de su abandono. Una fecha que encuentra su correspondencia, como se detallara a continuación, con el momento de construcción de la piscina bautismal sur (Fernández et al., 2019: 5698-5700). Así pues, los datos estratigráficos de la piscina septentrional permiten encuadrar su edificación entre mediados del S. IV y su probable abandono en torno al inicio del S. V. Una horquilla temporal que indica el corto período de tiempo en que la estructura estuvo en uso.

El estudio cronoestratigráfico fue cruzado con análisis arqueométricos: dataciones absolutas de ${ }^{14} \mathrm{C}$ y luminiscencia ópticamente estimulada -OSL- sobre diferentes materiales de las estructuras bautismales ${ }^{2}$. Los resultados de este trabajo se presentan de manera resumida en las Tablas 1 y 3 . En el caso de la piscina norte se observa que las dataciones obtenidas por OSL sobre mortero de cal, opus signinum y un ladrillo de la construcción, presentan una desviación típica bastante extensa que comporta, por este motivo, dilatados intervalos de tiempo. No obstante, si sobreponemos estos intervalos conseguimos establecer uno más preciso que se emplaza entre los años 312 y 385 . Una propuesta temporal reforzada por el análisis por ${ }^{14} \mathrm{C}$ de la muestra IV-7C (Tabla 1), que una vez calibrada arroja

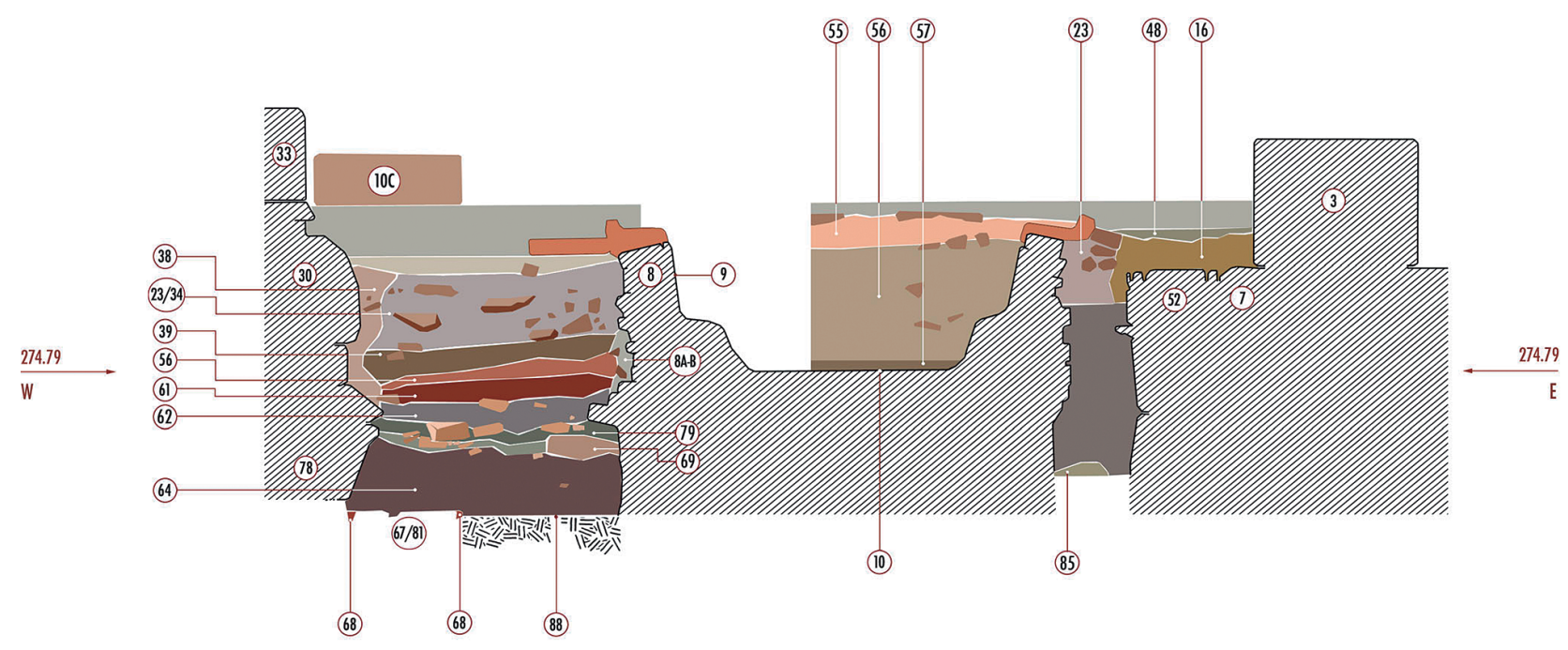

IDANHA-A-VELHA | NORTH BAPTISTERY | W-E

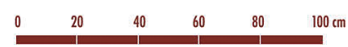

Fig.5. Perfil estratigráfico de la piscina bautismal norte. / Stratigraphic sequence of the north baptismal font.

\footnotetext{
2 Los análisis OSL fueron realizados por Jorge Sanjurjo-Sánchez de la Universidad de A Coruña.
} 


\begin{tabular}{|c|c|c|c|c|}
\hline \multirow{2}{*}{ Técnica } & Código de muestra & Tipo de muestra & Resultado BP & Intervalo de tiempo \\
\hline \multirow{3}{*}{ OSL } & IV-7A & Mortero & $1779 \pm 152$ & $81-385$ \\
\cline { 2 - 5 } & IV-7B & Ladrillo & $1612 \pm 188$ & $312-487$ \\
\cline { 2 - 5 } & IV-7C & Opus signinum & $1473 \pm 232$ & $307-771$ \\
\hline \multirow{2}{*}{${ }^{14} \mathrm{C}$} & & & & Cal A.C. \\
\hline & IV-7C & $\begin{array}{c}\text { Opus signinum } \\
\text { (parte carbonatada) }\end{array}$ & $1790 \pm 30$ & $68,6 \%-133-264$ \\
$26,8 \%-275-330$ \\
\hline
\end{tabular}

Table 1: Síntesis de los resultados de dataciones OSL y ${ }^{14} \mathrm{C}$ obtenidas sobre muestra de morteros, ladrillos y opus signinum de la estructura bautismal norte. Calibraciones obtenidas a través de la versión 3.10 de OxCal Program (Bronk, 2009) y basadas en la curva IntCal09 (Reimer et al., 2009). / Synthesis of the results of OSL and ${ }^{14} \mathrm{C}$ dating obtained on a sample of mortars, bricks and opus signinum of the northern baptismal font. Calibrations obtained through version 3.10 of OxCal Program (Bronk, 2009) and based on the IntCal09 curve (Reimer et al., 2009).

una datación situada entre los años 133-330 cal AD. Además, se realizaron dos análisis más por ${ }^{14} \mathrm{C}$ sobre material óseo. En primer lugar, la muestra Beta 505134 se corresponde con un hueso de animal recogido en el estrato de relleno más antiguo de la piscina norte -UE57-y, por lo tanto, depositado después de su abandono. En este caso, el intervalo de tiempo más fiable ha podido fijarse entre los años 131-326 cal AD. Este resultado es anterior a los materiales que han sido identificados en la misma unidad, los cuales permiten afinar su cronología entre finales del S. IV e inicios del S. V. De otro lado, a pesar de que los estratos localizados en el interior de la fons son una deposición secundaria conviene señalar que podrían contener tierras de contextos primarios diversos. Así pues, los materiales identificados acaban por convertirse en un terminus post quem de su momento de abandono. En segundo lugar, la muestra Beta 505135 se corresponde con un hueso humano procedente de un enterramiento dispuesto sobre las unidades que amortizaban la estructura bautismal y sin ninguna conexión con esta última. Su cronología es mucho más tardía, pudiendo datarse, probablemente, en el S. XIII (Tabla 2).

\subsection{La Piscina Sur}

Las intervenciones arqueológicas desarrolladas por J. Cristóvão pudieron recuperar parte de la estratigrafía anterior a su edificación, específicamente aquella no alterada por las excavaciones de F. Almeida. Los vestigios más antiguos, seccionados en su totalidad por la zanja de cimentación de esta pila cruciforme, se corresponden con los restos de diferentes paramentos asociados a una estructura de combustión -realizada en ladrillo- y a un pavimento de opus signinum (Fig. 3;
Fig. 6). Estas construcciones de cronología altoimperial y amortizadas en un momento indeterminado, son cubiertas por una sucesión de diferentes estratos de tierra que han sido identificados como parte de un basurero, cuyo uso se alargaría entre finales del S. IV e inicios del S. V (Fernández et al., 2019: 5699-5701).

Esta propuesta temporal se fundamenta, sobre todo, en el estudio del registro cerámico de la unidad más moderna cortada por la zanja de cimentación de la piscina -UE31-, definida por la presencia de formas de TS Africana D1 -un plato Hayes 61 A/B4 y un fragmento de una base decorada con un patrón alternado de palmetas y trifolios, estilo Hayes A (ii)-(III)- que permiten su datación entre finales del S. IV e inicios del S. V (Hayes, 1972, Bonifay, 2004, Fernández et al., 2019: 5699-5700). Además, se documenta la presencia de TS Hispánica transicional, de TS Hispánica Tardía -formas Ritt 8T y Drag.37T producidas en los valles de los ríos Ebro y Duero- y de un borde decorado en buril, que puede ser clasificado como una producción regional tardía de cerámica fina. Entre este registro destaca, también, una forma Drag. 37T con una decoración que puede encuadrarse en el segundo estilo decorativo y que apunta a una cronología próxima a los inicios del S. V. Por otro lado, dentro de la misma UE31, se halló un Nummus de Constancio II de la serie SECVRITAS REIP que puede datarse entre los años 337 y 340, (Fernández et al., 2019: 5699).

El resto de la secuencia estratigráfica está incompleta debido a la no conservación de los niveles de uso inmediatamente previos a la construcción de esta piscina (Fig. 6). Además, faltan las unidades que flanquearían su parte superior, así como la superficie de circulación asociada a su funcionamiento. Ausencias que impiden establecer con precisión su cronología de

\begin{tabular}{|c|c|c|c|}
\hline Código & Material & UE & Resultado BP \\
\hline Beta 505134 & Hueso animal & UE 57, relleno de la piscina bautismal & $1800 \pm 30$ \\
\hline Beta 505135 & Hueso humano & (UE10C) & $79,1 \%-131-260$ \\
$16,3 \%-279-326$ & $830 \pm 30$ \\
\hline
\end{tabular}

Table 2: Dataciones ${ }^{14} \mathrm{C}$ obtenidas sobre muestras de huesos identificados en las excavaciones de la estructura bautismal norte. Calibraciones obtenidas a través de la versión 3.10 de OxCal Program (Bronk, 2009) y basadas en la curva IntCal09 (Reimer et al., 2009). / ${ }^{14} \mathrm{C}$ dates obtained on bone samples identified in the excavations of the northern baptismal font. Calibrations obtained through version 3.10 of OxCal Program (Bronk, 2009) and based on the IntCal09 curve (Reimer et al., 2009). 


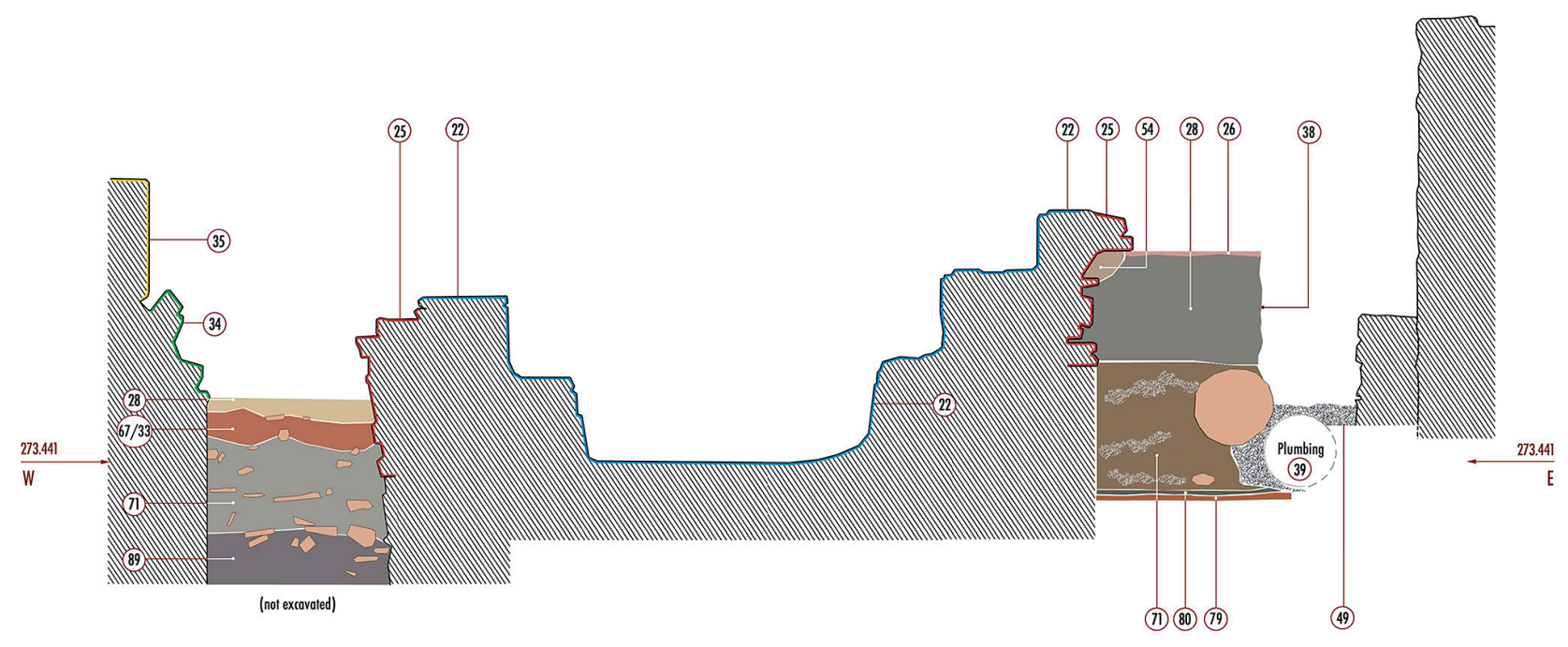

IDANHA-A-VELHA | SOUTH BAPTISTERY | W-E

Fig.6. Perfil estratigráfico de la piscina bautismal sur / Stratigraphic sequence of the south baptismal font.

construcción y uso. No obstante, teniendo en cuenta la cota superior de la estratigrafía conservada parece plausible suponer que los depósitos más recientes documentados estén próximos al nivel de circulación. Este sería el caso de la UE30, estrato excavado parcialmente durante la intervención dirigida por F. de Almeida y con una cota superior cercana a la altura máxima conservada de la piscina (Fernández Fernández et al., 2019: 5699-5700).

Las dataciones obtenidas por OSL en la piscina sur, resultante del análisis de morteros de construcción, opus signinum y un ladrillo de la estructura, presentan unas características similares a las ya comentadas en relación con la septentrional: la existencia de una desviación típica extensa. No obstante, la sobreposición de los intervalos temporales obtenidos permite acotar un lapso comprendido entre los años 316 y 473. Un período que puede ajustarse a los años 313-406 cal AD. gracias a la datación por ${ }^{14} \mathrm{C}$ de la muestra IV-4A (Tabla 3). Esta información fue complementada con otras dos dataciones por ${ }^{14} \mathrm{C}$ de restos orgánicos obtenidos en la UE31 (Tabla 4). La primera, Beta 505132, correspondiente a un carbón -Jara - Cistus L.- que pudo calibrarse con la máxima fiabilidad en el intervalo 284-391

\begin{tabular}{|c|c|c|c|c|}
\hline \multirow{2}{*}{ Técnica } & Código de muestra & Muestra & Resultado BP & Intervalo de tiempo \\
\hline \multirow{3}{*}{ OSL } & IV-4A & Mortero de junta & $1484 \pm 211$ & $316-739$ \\
\cline { 2 - 5 } & IV-4B & Ladrillo & $1725 \pm 187$ & $100-473$ \\
\cline { 2 - 5 } & IV-5 & Opus signinum & $1541 \pm 126$ & $345-597$ \\
\hline & & & & Cal A.C. \\
\hline${ }^{14} \mathrm{C}$ & IV-4A & $\begin{array}{c}\text { Opus signinum } \\
\text { (parte carbonatada) }\end{array}$ & $1700 \pm 30 \mathrm{BP}$ & $\begin{array}{c}74,8 \%-313-406 \\
23,6 \%-213-406\end{array}$ \\
\hline
\end{tabular}

Table 3: Síntesis de los resultados de dataciones OSL y ${ }^{14} \mathrm{C}$ obtenidas en la estructura bautismal sur. Calibraciones obtenidas a través de la versión 3.10 de OxCal Program (Bronk, 2009) y basadas en la curva IntCal09 (Reimer et al., 2009). / Synthesis of the results of OSL and ${ }^{14} \mathrm{C}$ dating obtained in the southern baptismal font. Calibrations obtained through version 3.10 of OxCal Program (Bronk, 2009) and based on the IntCal09 curve (Reimer et al., 2009).

\begin{tabular}{|c|c|c|c|c|}
\hline Código & Muestra & UE & Resultado BP & Cal A.C. \\
\hline Beta 505132 & Carbón (Jara-Cistus L.) & UE31 & $1720 \pm 30 B P$ & $95,4 \%-284-391$ \\
\hline Beta 505133 & Hueso de animal & UE31 & \multirow{2}{*}{$1700 \pm 30 \mathrm{BP}$} & $\begin{array}{l}74,8 \%-313-406 \\
23,6 \%-213-406\end{array}$ \\
\hline
\end{tabular}

Table 4: Dataciones ${ }^{14} \mathrm{C}$ obtenidas sobre muestras orgánicas identificadas en la estructura bautismal sur. Calibraciones obtenidas a través de la versión 3.10 de OxCal Program (Bronk, 2009) y basadas en la curva IntCal09 (Reimer et al., 2009). / ${ }^{14} \mathrm{C}$ dates obtained on organic samples identified in the southern baptismal font. Calibrations obtained through version 3.10 of OxCal Program (Bronk, 2009) and based on the IntCal09 curve (Reimer et al., 2009). 
cal AD. La segunda, Beta 505133, perteneciente a un hueso animal, ha podido ser calibrada con una certeza de $74.8 \%$ en el lapso de 313-406 cal AD.

En síntesis, es posible deducir que la construcción de la pila meridional se realizó a inicios del S. V. Por el contrario, la falta de datos precisos impide establecer una hipótesis fundamentada sobre su tiempo de uso o sobre el momento de su abandono.

\section{PISCINAS BAUTISMALES E INTERPRETA- CIÓN HISTÓRICA EN IDANHA-A-VELHA}

El conocimiento obtenido sobre la ocupación previa a la construcción de la piscina bautismal norte permite avanzar en el debate abierto en relación con la configuración urbana de Igaedis, ya que es en esta área donde tradicionalmente se ha propuesto emplazar parte del trazado de su decumanus maximus. Una hipótesis fundamentada en la idea que F. de Almeida (1956:90) presentó sobre la fosilización en Idanha-a-Velha de la trama urbana romana. A pesar de que esta tesis no ha podido ser confirmada arqueológicamente, estudios posteriores la han aceptado como válida (García, 1986: 101-102; Cristóvão, 2005: 194) e, incluso, se han servido de ella para proponer la restitución sincrónica de las principales vías del trazado romano (Sánchez y Morín, 2014: 36). No obstante, la presencia de una estructura doméstica de cronología augustea bajo la piscina septentrional, abre nuevamente el debate sobre la configuración de la malla urbana igaeditana y pone en cuestión las afirmaciones realizadas. Por este motivo, tampoco parece acertado seguir la propuesta de F. de Almeida (1956: 92), continuada por I. Sánchez y J. Morín (2018: 628), sobre la localización del cruce del decumanus y el cardo maximus en la actual plaza del Pelourinho, donde además emplazaron el antiguo foro romano. Un espacio en el que V. Mantas (2010: 185) ha propuesto la presencia de un anfiteatro por la comparación del caso igaeditano con los cercanos ejemplos de Bobadela -Oliveira do Hospital, Portugal- y Conimbriga -Condeixa-a-Velha, Portugal-.

La intervención dirigida por F. de Almeida a lo largo del frente norte de la Sé de Santa María, pudo haber afectado a la conservación de los primeros escalones y al nivel de circulación asociado a la piscina bautismal. No obstante, también es posible que esta destrucción se produjese durante un momento indeterminado del período medieval, cuando esta zona se convirtió en cementerio tras la cesión de la ciudad a la Orden del Temple en 1165 (Fernández et al, 2019: 5695). Contexto donde se integraría el enterramiento del que se extrajo el material óseo datado por ${ }^{14} \mathrm{C}$ (Beta 505135-Tabla 2). Por otro lado, cabe destacar que será durante la realización de los trabajos dirigidos por F. de Almeida cuando se documentaron las diferentes estructuras en sillería y sillarejo, que parecen formar una planta tripartita en relación con la división interna de la Sé de Santa María. En el espacio occidental se localiza la piscina bautismal, en el central se abre una amplia estancia cuadrangular y en el oriental se encuentra el ya mencionado espacio con suelo de opus signinum. Estancia donde se ha localizado el primer altar mayor de la catedral visigoda (Almeida, 1977: 52). Una hipótesis continuada por algunos investigadores (Fernandes 2006: 63), a pesar de la aparición de otras teorías que definen aquí los restos de un narthex (Ferreira de Almeida, 1986: 45).

El descubrimiento de la piscina bautismal septentrional (Cristóvão, 2002: 14-15) y la lectura arqueológica de la Sé de Santa María (Caballero, 2006), relanzaron el debate sobre la interpretación de los restos arquitectónicos localizados en el frente norte de esta iglesia. Como ya se ha referido anteriormente, P. A. Fernandes (2006: 63) planteó, prudentemente, la presencia de una basílica conectada con la piscina norte y con el supuesto altar mayor de la catedral visigoda. Una hipótesis adoptada por I. Sánchez y J. Morín (2014: 69-70), quienes identifican aquí una iglesia de planta tripartita similar a las documentadas en el área catalana y el mediodía francés. Este edificio englobaría, también, el altar mayor y la pila bautismal, estructura que utilizan, siguiendo el trabajo de J. Cristóvão (2002: 14-15), como fósil director para proponer su datación entre los siglos IV-V y considerarlo, en consecuencia, el primer establecimiento cristiano egitano. Además, suponen que este complejo fue remodelado en el S. VI debido al nombramiento de la ciudad como sede episcopal, circunstancia que facilitaría la construcción de un nuevo conjunto eclesiástico. Esta tesis se inserta dentro de un marco de reinterpretación general de los vestigios localizados en este sector de la aldea de Idanha-a-Velha (Sánchez y Morín, 2014: 68-104). Una nueva lectura que incluye estos elementos dentro de un cuadro de evolución histórica enfocado en la realidad episcopal de Egitania. Sin embargo, esta hipótesis es difícilmente admisible por diferentes motivos, entre los que cabe destacar:

i) la tendencia a unificar estructuras dentro del mismo plano constructivo sin que sea posible aseverar su pertenencia al mismo arco temporal;

ii) la escasez de secuencias estratigráficas que permitan plantear relaciones físicas y temporales precisas;

iii) o la evocación de criterios tipológicos e histórico-artísticos ante la carencia/ausencia de un registro material con una dimensión cronoestratigráfica segura que fundamente sus propuestas.

Las tesis presentadas coinciden en englobar las construcciones localizadas en este espacio dentro del mismo plano estratigráfico, especialmente aquellas cuya conexión permiten esbozar la planta de una basílica con baptisterio. No obstante, las excavaciones arqueológicas desarrolladas aquí (Fernández et al., 2019: 5698-5700) han constatado que esta relación estructural es errónea. Esta piscina bautismal no tiene una conexión estratigráfica con las construcciones mencionadas, presentando, exclusivamente, una correspon- 
dencia cronológica con los restos de dos pavimentos de opus signinum (N. os 1 y 2, Fig. 7) que, a su vez, se adosan a una edificación (N. ${ }^{\circ}$, Fig. 7 ) realizada en mampostería y de la que se conserva una esquina y un acceso (N. ${ }^{\circ}$ 5, Fig. 7). Este registro material, localizado al oeste de esta pila, se identificaría con los restos del edificio/estancia que englobaría a la piscina. Un probable baptisterio cuya utilización, siguiendo esta hipótesis de trabajo, puede datarse entre mediados del S. IV e inicios del S. V (Fernández et al., 2019: 5704-5705). Sin embargo, no se puede conectar esta edificación con la presencia aquí de una basílica, a pesar de ser una tesis plausible, debido a la falta de un registro material que permita asegurar tal posibilidad. Los paramentos realizados en sillería y sillarejo que parecen formar una planta tripartita son posteriores a la pila bautismal, rompiendo sus zanjas de cimentación los muros y pavimentos asociados cronológicamente a ella. Además, cabe destacar que el paramento que separa la estancia occidental de la central impediría (Muro 3, Fig. 5; N. ${ }^{\circ}$ 3, Fig. 7), físicamente, la salida del bautizado de la fons. Así pues, a tenor de esta documentación, parece acertado rechazar la hipótesis de I. Sánchez y J. Morín (2014: 69-70), aunque no puede negarse la presencia de una basílica posterior según lo argumentado por P. A. Fernandes (2006: 63). Hipótesis fundamentada en la lectura estratigráfica que realizó $L$. Caballero (2006: 269-270) de esta zona.

La piscina bautismal meridional presenta una problemática similar a la ya discutida en relación con la septentrional. En este caso, tampoco existe un acuerdo sobre su organización litúrgica, cronología o articulación con las estructuras localizadas en su entorno inmediato. No obstante, los recientes trabajos arqueológicos han aportado una valiosa información a la hora de intentar disipar algunas de las cuestiones planteadas (Fernández et al., 2019: 5696-5698). En primer lugar, cabe destacar que la piscina se inserta dentro de una única zanja de cimentación y que su estudio detallado no muestra que su planta cruciforme sea producto de diferentes momentos constructivos. Por el contrario, toda la estructura sería realizada al mismo tiempo. Este dato invalidaría la tesis de T. Ulbert (1978: 150) sobre la anexión de las pilas laterales a la central en un segundo momento y su vinculación con la generalización del bautismo infantil a lo largo del S. VI. Sin embargo, no parece que este hecho resuelva la cuestión en favor de la propuesta lanzada por C. Godoy (1986: 135), razón por la cual parece prudente dejar el análisis de esta cuestión litúrgica hasta que nueva información arroje más luz a este debate. En segundo lugar, el hecho de que su construcción pueda ser encuadrada a inicios del S. V, probablemente al mismo tiempo en que se amortizaba la piscina septentrional, abre nuevas perspectivas sobre su integración dentro del yacimiento idanhense. No obstante, a pesar de que diferentes investigadores coincidieron en señalar la anterioridad de esta fons en relación con la Sé de Santa María (Torres, 1992: 179; Cristóvão, 2002: 22; Fernandes, 2006: 54; Caballero, 2006: 270-271), no existen datos arqueológicos que permitan afirmar con claridad su vinculación con una posible basílica visigoda. Esta idea es seguida por I. Sánchez y J. Morín (2014: 71-72), quienes localizan en esta área un baptisterio exento de planta cuadrangular conectado a una basílica similar a la de Torre de Palma y datada en el S. VI, que coincidiría con la elevación de la ciudad a la dignidad episcopal. Una tesis fundamentada en la reinterpretación de algunos vestigios materiales (algunos de ellos ocultos a la vista actual) y de antiguas planimetrías de excavación (que no presentan una lectura cronoestratigráfica). Además, del establecimiento de paralelismos con otros complejos religiosos encuadrados en esta centuria. Esta idea no puede

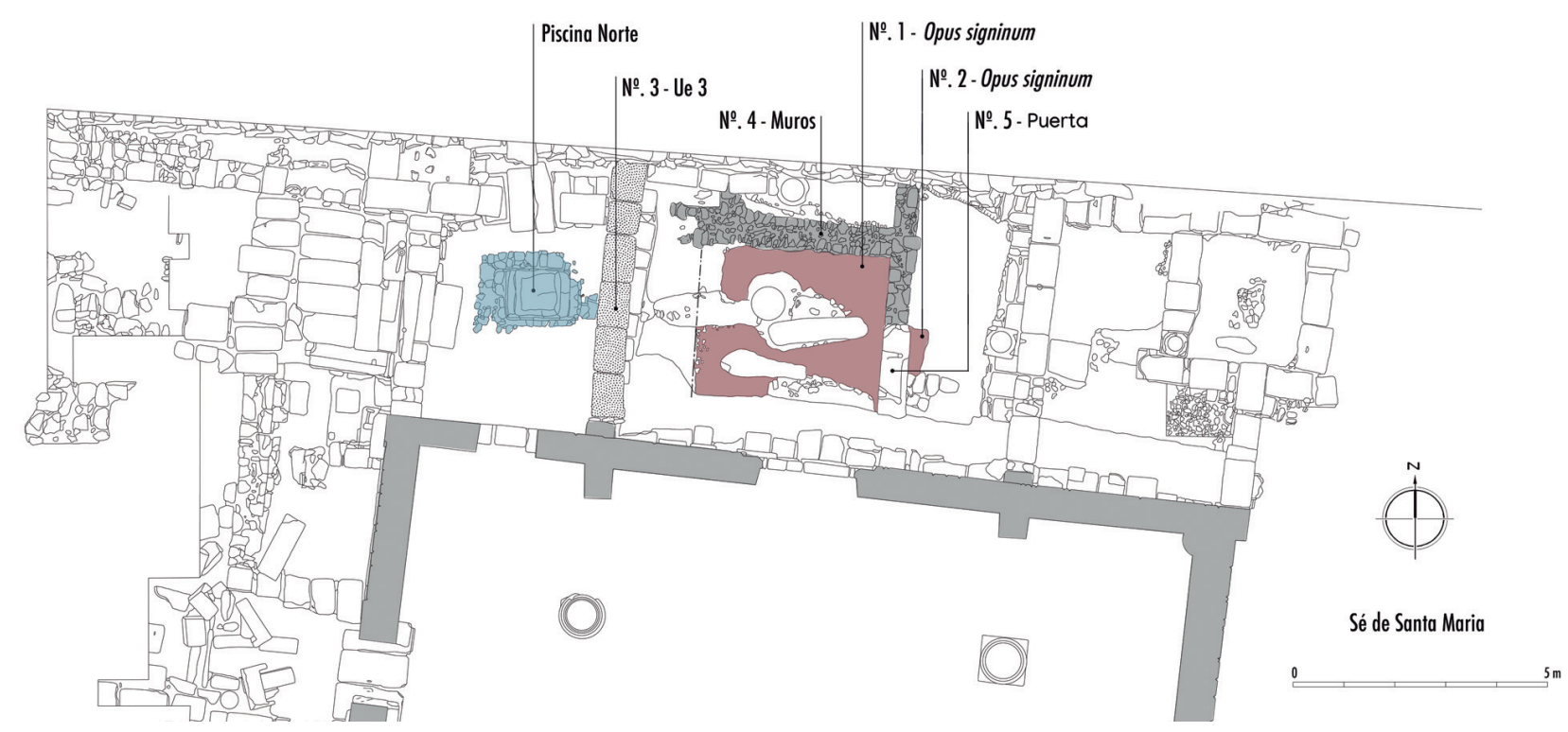

Fig.7. Estructuras documentadas al norte de la Sé de Santa María. / Documented structures in front of the north facade of the Sé de Santa María. 
aceptarse ya que no es posible emplazar dentro del mismo período las estructuras referidas al propuesto baptisterio, mientras que las excavaciones realizadas en la zona donde apuntan la presencia de una iglesia semejante a la de Torre de Palma no arrojan datos que permitan localizar aquí una edificación de este tipo.

Por otro lado, la analogía establecida entre las piscinas de Idanha-a-Velha y Torre de Palma fue establecida partiendo de criterios histórico-artísticos que databan la construcción de ambas estructuras en el S. VI. No obstante, son muchas las dudas planteadas con relación a la cronología, funcionalidad y adscripción religiosa de Torre de Palma (Godoy, 1995: 294-303; Chavarría, 2007: 216-217; Piay, 2011: 275-276). Situación a la que se suma la nueva datación establecida para el caso egitano. Así pues, parece razonable descartar la supuesta correspondencia entre ambas piscinas.

\section{CONSIDERACIONES GENERALES}

El análisis crítico de la diferentes tesis relativas a la contextualización histórico-arqueológica de las piscinas bautismales norte y sur, muestra que muchas de ellas son suposiciones construidas sobre datos incompletos o inexistentes. Una realidad a la que se suma el inesperado giro que ha supuesto la nueva documentación arqueológica generada por las últimas intervenciones realizadas en las pilas egitanas (Fernández et al., 2019). Así pues, a tenor de la información disponible, sólo parece posible aseverar en torno a ellas los siguientes puntos:

i) el uso de la piscina septentrional puede encuadrarse en la segunda mitad del S. IV e inicios del S. $V$, tiempo en que, posiblemente, estaría incluida dentro de un baptisterio que no tiene todavía una definición material concreta;

ii) la construcción de la piscina meridional puede fecharse a inicios del S. V, aunque no es posible precisar su tiempo de uso y su relación con el resto de las estructuras que le serían coetáneas, siendo posteriores las localizadas en su entorno inmediato.

Por otro lado, cabría reseñar que la cronología de uso de la pila bautismal norte ha podido ser acotada gracias a los diferentes materiales recuperados en su interior, que indican una fecha de abandono muy cercana (de pocas décadas) a la de construcción. Así pues, cabe la posibilidad de que la piscina meridional sucediese sin interrupción a la septentrional.

El abandono o amortización de las diferentes construcciones altoimperiales localizadas en el entorno donde se emplaza la Sé de Santa María, puede datarse en un momento anterior a las décadas centrales del S. IV. Esta situación sumada a la documentación procedente de otros lugares de la ciudad indicaría que la transformación de su paisaje urbano se produciría durante la primera mitad de esta centuria, originada, tal vez, por la construcción del recinto amurallado egitano (Carvalho et al., en prensa). La cerca de Idanha-a-Velha, levantada gracias al expolio masivo de los materiales que conformaron la capital de la civitas Igaeditanorum durante el período altoimperial, es otro de los monumentos de este yacimiento arqueológico que más atención ha despertado en la historiografía especializada (De Man, 2011: 171-175). Este precinto defensivo acoge dentro de su perímetro un núcleo urbano de menor extensión que el altoimperial (Cristóvão, 2005: 197), datándose su obra entre finales del S. III e inicios del S. IV (Cristóvão, 2002: 6). Una datación sustentada por los trabajos arqueológicos desarrollados en los sitios de Lagar de Varas (Cristóvão, 2002: 27-28) y Chão da Muralha (Carvalho et al., en prensa).

La edificación de la cerca egitana no es un fenómeno desconocido en la Lusitania de este momento (De Man, 2011: 239-245), destacándose la aparente proximidad cronológica existente entre la construcción de la piscina septentrional y la cerca urbana. Una estructura que a su evidente carácter defensivo se le debe sumar una función de prestigio y de delimitación de una ciudad que puede no haber sido dotada, al menos así parece a tenor de los datos disponibles (Cristóvão, 2005: 193-194), de una muralla durante el período altoimperial. Característica que comparte con otros casos como Bracara Augusta -Braga, Portugal- o Lucus Augusti -Lugo, España- (Diarte y Gurt, 2015: 323). De otro lado, la construcción de esta cerca anunciaría la importancia que Egitania alcanzó durante el período suevo-visigótico (Cordero, 2019: 500-502). Así pues, su edificación tal vez pueda vincularse, al igual que en el resto de la península, con el inicio de un nuevo modelo urbano y, tal vez, con la consolidación del poder religioso egitano (Diarte y Gurt, 2015: 321-325).

La cronología del baptisterio septentrional se emplaza en la misma centuria en que se ha fechado el primer conjunto episcopal de Barcelona -España-, dotado de una basílica y una fuente bautismal de planta cuadrada (Beltrán, 2013: 23-24), y la Fase Pre-episcopal III del complejo de Egara -Tarrasa, España-, también con una piscina cuadrangular (García et al., 2009: 80-92). Ambos casos están bien constatados arqueológicamente y el establecimiento de un paralelo con el caso egitano es sencillo. No obstante, conviene recordar que no parece factible establecer un paralelo entre estos ejemplos debido a la carencia de datos que presenta todavía el caso idanhense, aún con muchas preguntas abiertas. Este problema relativo al conocimiento de cómo el cristianismo se fue consolidando en el paisaje de Egitania es extensible al resto de la Lusitania romana y, también, a su capital, Emerita. Un importante centro político y administrativo dentro de la estructura imperial tardorromana y sede de una de las comunidades cristianas hispanas más antiguas. Una congregación consolidada y organizada en el S. IV (Vilella, 1998: 277-285), con un registro material evidente en los alrededores de la actual iglesia de Santa Eulalia de Mérida, aunque sin una constatación clara en 
el espacio intramuros. Manifestaciones cristianas que convivirían con la todavía importante tradición pagana, caracterizándose a lo largo de esta centuria una ciudad que urbanística y culturalmente estaría definida por su dualidad pagano-cristiana (Mateos, 2018: 135-137).

En este contexto de expolio, construcción, continuidad y transformación, es donde debería incluirse el caso egitano. Ciudad donde la aparición de una estructura bautismal no parece, sin embargo, bagaje suficiente para suponer un proceso generalizado de cristianización de su paisaje urbano o su sociedad. Así pues, el caso de civitas Igaeditanorum se encuadraría dentro del marco general propuesto para el urbanismo hispano tardorromano, en el que puede rastrearse una progresiva infiltración del cristianismo en un marco caracterizado por un paisaje urbano continuista con el período anterior y con núcleos donde, como en el caso de Emerita (Mateos, 2018), aún es posible constatar una importante actividad edilicia. En este contexto, la presencia de manifestaciones urbanas cristianas durante el S. IV parece ser minoritaria y con un escaso impacto en la transformación del urbanismo. Según los datos disponibles, durante esta centuria, la mayoría de las ciudades tenían solo un área de entierro cristiano relacionada con un mártir local. Sin embargo, en algunos de los complejos episcopales, la construcción de la catedral comenzó en los últimos años del siglo, comúnmente dentro de las murallas de la ciudad. Un marco histórico extensible también a los primeros años del S. V (Gurt y Sánchez, 2010; Diarte y Gurt, 2015; Ruiz, 2018; Chavarría, 2018).

De otro lado, el pretender explicar por qué se produjo esta sucesión de piscinas bautismales es un tema complicado debido a las carencias que, todavía, presenta la documentación disponible. Circunstancia que dificulta la edificación una tesis sólida. No obstante, parece razonable avanzar algunas hipótesis de trabajo sobre las que enfocar futuras líneas de investigación. Así pues, se podría considerar que:

i) Ambas pilas bautismales denotarían la existencia de un episcopio en Egitania durante este período. Esta posibilidad, ya planteada por F. de Almeida (1965: 136), no tiene hoy en día una base documental o material que permita confirmar su configuración. No obstante, en este sentido, conviene recordar que la primera mención a la presencia de una estructura episcopal en la ciudad -la alusión de Adoricus como Egestanae episcopus en el denominado Concilio de Lucus del año 569- reconoce una entidad ya constituida previamente (Cordero, 2019: 490-491). La fecha de su creación es todavía desconocida, aunque no puede descartarse la posibilidad de que se remonte, por lo menos, al S. V.

ii) Las piscinas bautismales egitanas serían una muestra de la enconada disputa que mantuvo la iglesia católica contra el priscilianismo o el maniqueísmo, herejías con una patente implantación en la Lusita- nia de la segunda mitad del S. IV. En este sentido, la construcción de la pila meridional podría estar relacionada con el abandono de un espacio bautismal vinculado con uno de estos movimientos heterodoxos, en cuya lucha se destacaron el obispo Itacio de Ossonoba -Faro, Portugal- e Hidacio de Emerita. En esta ciudad, el conflicto maniqueista llegaría a originar tumultos violéntos, posiblemente coincidiendo con la presencia aquí de un doctor de la iglesia maniquea romana (Chadwick, 1976: 93-94; San Bernardino, 1997; Escribano, 2003). Así pues, parece licito plantearse como hipótesis de trabajo que las estructuras bautismales analizadas se inscriban en este marco histórico-religioso, aunque por ahora no existan datos concretos que permitan vincular a Egitania con estos hechos.

Una vez abierto este debate de carácter más religioso, queremos señalar que no es nuestra intención profundizar en el estudio de las diferentes cuestiones litúrgicas vinculadas con las piscinas egitanas. Este análisis se presentará en un trabajo monográfico que esperamos presentar en breve. No obstante, parece adecuado resaltar que la aparente diferencia entre ambas estructuras no las convierte en un ejemplo único. Por el contrario, su diversidad se inscribe dentro de la heterogeneidad que caracteriza la edificación de este tipo de estructuras durante este período (Wood, 2006; Ferguson, 2009; Jensen, 2011; Brandt, 2011).

iii) Por último, no puede descartarse que la construcción de la piscina meridional a inicios del S. V estuviese relacionada con la monumentalización/sustitución del primigenio espacio bautismal norte. Una tesis que nos lleva de nuevo a considerar como posible la existencia de un episcopio en Egitania ya en la segunda mitad del S. IV.

\section{AGRADECIMIENTOS}

Este trabajo se encuadra dentro del Proyecto de Investigación Plurianual (DGPC: 2016-2019) titulado IGAEDIS. Da civitas Igaeditanorum à Egitânia. A construcción e evolução da cidade e a definição dos seus territórios da Época Romana até à doação dos Templários (séculos I a XII), eje 3, ejecutado en el ámbito de un protocolo firmado entre el Município de Idanha-a-Nova, la Universidade de Coimbra (FLUC), la Universidade Nova de Lisboa (FCSH) y la Direção Regional de Cultura do Centro. Además, agradecemos a José Luís Madeira (FLUC) el tratamiento de las figuras 1, 5, 6, y 7.

\section{BIBLIOGRAFÍA}

Almeida, F. de, 1956. Egitânia: história e arqueologia. Universidade de Lisboa, Lisboa.

Almeida, F. de, 1965. O baptistério paleocristão de Idanha-aVelha (Portugal). Boletín del Seminário de Estudios de Arte y Arqueologia XXXI, 134-136. 
Almeida, F. de, 1977. As ruínas romanas e visigóticas de Idanha-a-Velha. Anais 24-II, 41-57.

Beltrán, J., 2013. Barcelona, de colònia romana a sede regia visigoda, medina islàmica i ciutat comtal: una urbs en transformació. Quaderns d'Arqueologia i Història de la Ciutat de Barcelona 9, 16-118.

Brandt, O., 2011. Understanding the Structure of Early Christian Baptisteries. In: Hellholm, D., Vegge, T., Norderval, $\varnothing$ y Hellholm, Ch. (Eds.), Ablution, Initiation, and Baptism Late Antiquity, Early Judaism, and Early Christianity, 587-609. De Gruyter, Berlin

Bronk, C., 2009. Bayesian analysis of radiocarbon dates. Radiocarbon 51-1, 337-360. https://doi.org/10.1017/ S0033822200033865

Caballero, L., 2006. Aportaciones de la lectura de paramentos a la polémica sobre la Sé de Idanha-a-Velha. In: Al-Ândalus. Espaço de mudanza. Balanço de 25 años de história e arqueologia medievais, 266-273. Campo Arqueológico de Mértola, Mértola.

Carvalho, P.C., 2009. O Forvm dos Igaeditani e os primeiros tempos da civitas Igaeditanorum (Idanha-a-Velha, Portugal). Archivo Español de Arqueología 82, 115-131. https://doi. org/10.3989/aespa.082.009.005.

Carvalho, P.C., 2012. O caminho do Douro na época romana. Da capital da civitas Igaeditanorum aos Territoria dos dos Lancienses, Aravi, Meidubrigensis e Cobelci. In: Cubas, N., Hidalgo D., Salinas, M. (Eds.), Arqueología, patrimonio, prehistoria e historia antigua de los pueblos "sin pasado" ecos de la Lusitania en Arribes del Duero, 125-138. Universidad de Salamanca, Salamanca.

Carvalho, P.C., Fernández, A., Cristóvão, J., Dias, P., Costeira, R. (en prensa). Una primera aproximación a los contextos cerámicos tardoantigüos de Idanha-a-Velha (Egitania). Un ejemplo de importación y producción local en el interior de la provincia Lusitania. In: Rei Cretaria Romanae Fautores Acta 46. Marketing of Roman pottery: economic relationships between local and imported products, 49-91. Archaeopress Publishing, Oxford.

Chavarría, A., 2007. El final de las villae en Hispania (siglos IV-VII d. C.). Brepols, Turnhout.

Chavarría, A., 2018. A la sombra de un Imperio: iglesias, obispos y reyes en la Hispania tardoantigua. Edipuglia, Bari.

Cordero, T., 2018. Egitania: ciudad y territorio durante el periodo suevo-visigodo. In: Martín, I. (Ed.), Fortificaciones poblados y pizarras. La Raya en los inicios del Medievo, 110-120. Ayuntamiento de Ciudad Rodrigo, Ciudad Rodrigo.

Cordero, T., 2019. La organización de la diocesis Egitaniensis y la configuración territorial del interior de Lusitania durante la Alta Edad Media (400-800). Anuario de Estudios Medievales 49-2, 479-508. https://doi.org/10.3989/aem.2019.49.2.04.

Cristóvão, J., 2002. A aldeia histórica de Idanha-a-Velha. Câmara de Idanha-a-Nova, Idanha-a-Nova.

Cristóvão, J., 2005. Breve estudo sobre a organização do espaço público e os equipamentos urbanos da cidade de Idanha-a-Velha (dos finais do século I a.C. ao limiar do século IV). In: Actas das 2as Jornadas de Património da Beira Interior: Lusitanos e Romanos no Nordeste da Lusitânia, 189-204. Centro de Estudos Ibéricos, Guarda.

De Man, A. de., 2011. Defensas urbanas tardías de Lusitânia. Museo Nacional de Arte Romano, Mérida.
Diarte, P., Gurt, J. M., 2015. La percepción del espacio en el urbanismo tardoantiguo: Características evolutivas en el ejemplo hispano. Antiquite Tardive 23, 307-28. https://doi.org/10.1484/J.AT.5.109386.

Díaz, P. C., 2011. El reino Suevo (411-585). Akal, Madrid.

Escribano, V., 2003. La cuestión Priscilianista. In: Sotomayor, M. y Fernández, J. (Eds.), Historia del cristianismo I. Mundo Antiguo, 459-480. Trotta, Madrid

Ferguson, E., 2009. Baptism in the Early Church: History, Theology, and Liturgy in the First Five Centuries. Eerdmans, Grand Rapids.

Fernandes, P.A., 2006. Antes e depois da Arqueologia da Arquitetura: um novo ciclo na investigação da mesquita-catedral de Idanha-a-Velha. Artis 5, 49-72.

Fernández, A., Carvalho, P.C., Cristóvão, J., Sanjurjo-Sánchez, J., Dias, P., 2019. Dating the early Christian baptisteries from Idanha-a-Velha-the Suebi-Visigothic Egitania: stratigraphy, radiocarbon and OSL. Archaeological and Anthropological Sciences 11-10, 5691-5704. https://doi.org/10.1007/s12520019-00901-9

Ferreira de Almeida, C.A., 1986. Arte da Alta Idade Media. Alfa, Lisboa.

García, G., Moro, A., Tuset, F., 2009. La seu episcopal d'Egara. Arqueologia d'un conjunt cristià del segle IV al IX. Institut Català d'Arqueologia Clàssica, Tarragona.

García, L., 1986. Las transformaciones de la topografía de las ciudades en Lusitania en la Antigüedad Tardía. Revista de Estudios Extremeños 42, 93-114.

Godoy, C., 1986. Reflexiones sobre la funcionalidad litúrgica de pequeñas pilas junto a piscinas mayores en los baptisterios cristianos hispánicos. In: Actas del I Congreso Nacional de Arqueología Medieval Española, 125-137. Diputación General de Aragón, Zaragoza

Godoy, C., 1995. Arqueología y liturgia. Iglesias hispánicas (siglos IV al VIII). Universidad de Barcelona, Barcelona.

Gurt, J.M., Sánchez, I., 2010. Topografía cristiana en Hispania durante los siglos V y VI. Zona Arqueológica 11, 320-345.

Jensen, J., 2011. Living Water: Images, Symbols, and Settings of Early Christian Baptism. Brill, Leiden.

Jorge, A.M.C.M., 2002. L'épiscopat de Lusitanie pendant l'Antiquité tardive: (IIIe-VIle siècles). Instituto Português de Arqueologi, Lisboa.

Mantas, V.G., 2010. Ammaia e Civitas Igaeditanorum: Dois espaços forenses lusitanos. In: Nogales, T. (Ed.), Ciudad y foro en la Lusitania romana, 167-188. Museo Nacional de Arte Romano, Mérida.

Maloney, S.J., Hale, J.R., 1996. The villa of Torre de Palma (Alto Alentejo). Journal of Roman Archaeology 9, 275-94. https://doi.org/10.1017/S1047759400016639.

Mateos, P., 2018. De capital de la diócesis Hispaniarum a sede temporal de la monarquía sueva. La transformación del urbanismo en Augusta Emerita durante los siglos IV y V. In: Sánchez, I., Mateos, P. (Eds.), Territorio, topografía y arquitectura de poder durante la Antigüedad Tardía, 127-115. Consejo Superior de Investigaciones Científicas, Mérida.

Palol, P., 1967. Arqueología cristiana de la España romana. Siglos IV-VI. Consejo Superior de Investigaciones Científicas, Madrid. 
Piay, D., 2011. Arqueología y Priscilianismo. Hispania Antiqva $X X X V, 271-300$.

Pliego, R., 2009. La moneda visigoda. Historia monetaria del reino visigodo de Toledo (c. 569-711). Universidad de Sevilla, Sevilla.

Real, M.L., 2000. Portugal: cultura visigoda e cultura moçárabe. In: Caballero, L. y Mateos, P. (Eds.), Visigodos y Omeyas. Un debate entre la Antigüedad Tardía y la Alta Edad Media, 21-75. Consejo Superior de Investigaciones Científicas, Madrid.

Reimer P.J., Bard, E., Bayliss, A., Beck, J.W., Blackwell, P.G., Bronk, C., Buck, C.E., Cheng, H., Edwards, R.L., Friedrich, M., Grootes, P.M., Guilderson, T.P., Haflidason, H., Hajdas, I., Hatté, C., Heaton, T.J., Hoffmann, D.L., Hogg, A.G., Hughen, K.A., Kaiser, K.F., Kromer, B., Manning, S.W., Niu, M., Reimer, R.W., Richards, D.A., Scott, E.M., Southon, J.R., Staff, R.A., Turney, C.S.M y Van Der Plicht, J., 2013. IntCal13 and Marine13 Radiocarbon Age Calibration Curves 0-50,000 Years cal BP. Radiocarbon 55-4, 1869-1887. https://doi.org/10.2458/ azu_js_rc.55.16947.

Ruiz, M., 2018. Dinámicas topográficas urbanas en Hispania. El espacio intramuros entre los siglos II y VII d. C. Edipuglia, Bari.

Torres, C., 1992. A Sé Catedral da Idanha. Arqueologia Medieval 1, 169-178.

Sánchez, I., Morín, J., 2014. Idanha-a-Velha. Portugal. El espiscopio de Egitania en época tardoantigüa. AUDEMA, Madrid.
Sánchez, I., Morín, J., 2018. Topografía y forma urbis de Idanha-a-Velha en épocas romanas y tardoantigüa. In: Atas do VIII Encontro do Arqueologia do Sudoeste Peninsular, 623-634. Câmara Municipal de Serpa, Serpa.

Sánchez-Palencia, F.J., Pérez, L., 2005. Minería romana de oro en las cuencas de los ríos Erges / Erjas y Bazágueda (Lusitania): la zona minera de Penamacor-Meimoa. In: Lusitanos e Romanos no Nordeste da Lusitânia: Actas da 2as Jornadas de Património da Beira Interior, 267-307. Centro de Estudos Ibéricos, Guarda.

Schlunk, H., Hauschild, T., 1978. Hispania Antiqua. Die Denkmäler der frühchristlichen und westgostichen Zeit. Phillip von Zabern in Wissenschaftliche Buchgesellschaft, Mainz.

Ulbert, T., 1978. Frühchristliche Basiliken mit doppelapsiden auf der Iberischen. Deutsches Archäologisches Institut, Munich.

Vilella, J., 1998. Las primacías eclesiásticas en Hispania durante el siglo IV. POLIS. Revista de ideas y formas políticas de la Antigüedad Clásica 10, 269-285.

Wood, J., 2006. Elites and Baptism: Religious 'Strategies of Distinction' in Visigothic Spain. Studies in Church History 42, 3-17. https://doi.org/10.1017/S0424208400003806. 